\title{
As diversas fronteiras da América Meridional: alianças e inimizades com infiéis no século XVIII
}

\author{
The many frontiers of South America: alliances and conflicts with infidels \\ in the 18th century
}

\author{
Guilherme Galhegos Felippe* \\ Pontifícia Universidade Católica do Rio Grande do Sul (PUCRS), Porto Alegre, RS, Brasil \\ Maria Cristina dos Santos ${ }^{\star *}$ \\ Pontifícia Universidade Católica do Rio Grande do Sul (PUCRS), Porto Alegre, RS, Brasil
}

\begin{abstract}
RESUMO: A fronteira faz parte da constituição espacial e política da América Meridional. Nessa região, os conflitos gerados pela disputa e controle dos territórios tendem a acirrar-se à medida que avança o projeto colonial, fazendo com que surjam também, nas fronteiras, outras interfaces culturais. A categoria de índios infiéis, por oposição aos indígenas cristianizados, é recorrente na documentação colonial, convertendo-se numa ambígua categoria identificadora dos primeiros. O propósito desse texto é discutir as possibilidades de alianças e inimizades a partir da vinculação que se estabelece entre fronteira e infiel, na primeira quinzena do século XVIII.
\end{abstract}

PALAVRAS-CHAVE: América Meridional. Século XVIII. Fronteira e infiéis.

\begin{abstract}
Frontiers integrate the spatial and political constitution of South America. In this region, the conflicts generated by the struggle for territory and the maintenance of its control tend to escalate as the colonial project is developed, causing other cultural interfaces to arise in such frontiers. The label of infidel Natives, as opposed to Christianized Native Americans, is recurrent in colonial documents, becoming an ambiguous identifying category of the former. The purpose of this text is to discuss the possibilities of alliances and conflicts on the basis of the link that is established between the concepts of frontier and infidel, in the first fifteen years of the 18th century.
\end{abstract}

KEYWORDS: South America. 18th century. Frontier and infidels.

\footnotetext{
* Professor da Pontifícia Universidade Católica do Rio Grande do Sul (PUC-RS), Porto Alegre, RS, Brasil. Doutor em História pela Universidade do Vale do Rio dos Sinos (UNISINOS). E-mail: guilhermegfelippe@gmail.com https://orcid.org/0000-0003-4008-4926

** Professora da Pontifícia Universidade Católica do Rio Grande do Sul (PUC-RS), Porto Alegre, RS, Brasil. Doutora em História da América e Pós-Doutorado em Antropologia da América na Universidad Complutense de Madrid. E-mail:mcstita@pucrs.br https://orcid.org/0000-0002-7235-6335
} 
A América Meridional, onde hoje se situam os limites políticos entre Argentina, Uruguai e Brasil, é uma região privilegiada para múltiplos debates historiográficos, entre os quais se destaca o tema da fronteira. Desde o período colonial, com uma dimensão político-militar-diplomática, a noção de fronteira recebeu enfoques socioeconômicos, sendo definida como "terras livres" em recesso que vão sendo ocupadas conforme o avanço colonial (TURNER, 1893). Tal noção de fronteira - como linha ou "franja territorial" que avança sobre terras despovoadas a partir de iniciativas estatais - tem se renovado sob múltiplos enfoques conceituais e metodológicos (GUAZZELLI et al., 2009). Tau Golin (2002) apresenta o conceito de fronteira como construto para a discussão de região e nação, conceitos igualmente complexos para a história política da região sul do Brasil. As noções de fronteira e América Meridional parecem sinônimos entre o ser e o construir das identidades regionais ao longo do século XVIII. No século XIX, esse debate se inclinou para a questão pungente das identidades nacionais das jovens repúblicas latino-americanas. Mas, a fronteira também pode ser entendida como um espaço movediço em que se articulam distintas negociações movidas por diferentes interesses, inclusive dos indígenas, como demonstrou o estudo de Karina Melo (2017). Neste sentido, as práticas religiosas e culturais indígenas, que significaram a impossibilidade de execução de projetos civilizatórios, econômicos, evangélicos e, inclusive, científicos, "pueden verse como una interrupción a la colonización instrumentalizada por los miembros de un grupo fundamental a las colonias españolas” (VALLE, 2009, p. 9). A fronteira, ao invés de um diálogo, assemelhava-se muito mais a uma cacofonia, em que vizinhos querem a mesma coisa, mas alegam que têm direitos preferenciais (HERZOG, 2015, p. 1). É nessa perspectiva que utilizamos o conceito de fronteira no presente texto, ainda que com algumas variaçóes, como explicitaremos a seguir.

Durante o período colonial, a concepção ocidental de fronteira pressupunha uma área de disputa pelo controle de poder sobre os territórios. Contudo, fronteira só existe sob o ponto de vista de quem avança, pois para os grupos humanos que ali habitavam, "sus territorios eran el centro y no la frontera" (VALLE, 2009, p. 22-23). Resultava disto que a fronteira era o local onde estava o inimigo que deveria ser atacado e expulso. Nesse entendimento, os indígenas que se localizavam nessas zonas adquiriam imediatamente a condição de inimigos ${ }^{1}$.

Para os grupos nativos, numa visão holística, existem zonas de contato com os demais grupos que são vistas fundamentalmente como espaço de negociação, de relação com os demais. A fronteira existe para a relação e não contra ela: "fazer a guerra, por exemplo, é estabelecer uma relação tão relacional quanto fazer a paz” (STRATHERN, 1999, p. 169). Marylin Strathern estabelece, ainda, duas propriedades fundamentais para a "entidade” relação: ela é holográfica e complexa (2014, p. 277$)^{2}$. A partir destas propriedades, aponta alguns questionamentos, considerados oportunos para a presente análise:

O que acontece quando reunimos essas duas propriedades da relação (holografia e complexidade)? O que acontece quando consideramos que a entidade Relação se desloca por múltiplas escalas sem perder tais propriedades? No jargão do final do século XX, nosso pequeno construto começa a passar a impressão de ser um dispositivo que se auto-organiza (STRATHERN, 2014, p. 281, grifo do autor).

Nessa medida, se compreendermos que a guerra e a fronteira existem em função da relação entre diferentes grupos indígenas no período colonial, elas devem ser vistas como temas complementares 
e auto-organizativos das diversas circunstâncias em que as populações nativas foram registradas no início do século XVIII. Isto é, para os nativos, a guerra - coincidentemente na fronteira estabelece-se em função dos demais aspectos da vida compartilhada num determinado espaço e desloca-se em diferentes escalas, sejam as relações estabelecidas entre indígenas reduzidos ou não convertidos, sejam com missionários, autoridades civis, colonos ou mestiços. Se considerarmos que os registros coloniais foram produzidos a partir de um esquema mental em que a fronteira está definida pela presença dos inimigos, temos, então, que a condição dos indígenas pampianos, não cristianizados, os colocou como inimigos da e na fronteira cristã do avanço colonial. Tais observações parecem demasiado evidentes, mas a análise estrita dos dados documentais nos leva à reafirmação de que os infiéis são, invariavelmente, os inimigos. Concordar com esta constatação é dar razão a uma visão que só consegue perceber os eventos, e não os contextos. Apesar de balizar-nos por acontecimentos como ataques às estâncias e reduções, execução de tratados de paz e apresamento ou resgate de cativos, nossa preocupação metodológica recairá menos nestes eventos em si do que nas "práticas significativas" que os envolvem, preocupando-nos antes com "processos ambíguos do que com atos contidos ou incidentes isoláveis" por acreditar que a vida social é "uma atividade contínua” (COMAROFF, John; COMAROFF, Jean, 1992, p. 37).

Cabe pontuar que a narrativa registrada na documentação, produzida em função de um esquema mental da conquista colonial e espiritual (LUZ, 2003; LONDOÑ, 2002), vincula a fronteira como zona de guerra aos inimigos e tende a ser incorporada pela historiografia como a real descrição dos fatos, dando origem às interpretações que associam de forma imediata e dicotômica fronteira e guerra com inimigos e infiéis. Preferimos seguir o método de Ivonne del Valle, cujo interesse analítico não está em saber se os documentos condizem ou não com a realidade, mas, sim, analisar a realidade que dizem existir e que foi construída página a página em certas instâncias e transformou ou subsequentemente evitou em outros tipos de produções. Com isso, busca-se "evocar fragmentos de aquí y de allá no para fabricar una historia (la verdadera historia) de las fronteras, sino precisamente para mostrar lo que, sin embargo, siempre se nos escapa” (2009, p. 17).

Desde que Lévi-Strauss (1942) demonstrou que a guerra na sociedade indígena funciona mais como meio de troca, de relação com o outro, do que como forma de extermínio do inimigo, é possível questionar-se sobre quais motivos levam os grupos a empreender guerras, bem como acerca das atitudes indígenas registradas na documentação colonial, em especial aqueles comportamentos dos nativos discrepantes da lógica ocidental em reação a uma situação muito particular, como o rompimento de um tratado de paz logo após ser firmado com a sociedade colonial. Afinal, segundo a ótica ocidental, firmar um tratado de paz pressupóe uma relação diplomática - holográfica e complexa -, que deveria gerar a alteração do status de inimizade para o mais próximo possível do colaboracionismo. Já, entre as sociedades indígenas, o princípio da "relação com o outro" está num lugar prévio e fundamental (LÉVI-STRAUSS, 1991, p. 14): é mais uma relação, que não começa com a assinatura de um tratado de paz, tampouco termina em um eventual conflito.

No clássico estudo de Florestan Fernandes (1952) sobre a função social da guerra na sociedade tupinambá, temos que, desde o período colonial, a guerra se organiza em função da vingança - e esta última aparece como motor de uma sociedade que vive em função do passado. Ou seja, para este autor, os tupinambás sempre fizeram a guerra como vingança de um inimigo, a partir de uma agressão no passado. Criou-se, assim, um conjunto de ideias, utilizado por muito tempo como auto explicável: os indígenas vivem em função da guerra, que, realizada no presente, corresponde a uma 
vingança do passado, resultando no fato de que os índios representam uma sociedade apegada e/ou congelada no passado. Muitas vezes, essa compreensão foi utilizada para explicar a espiritualidade das sociedades indígenas, que as levava a ter um comportamento escapista de um presente no qual não sabem como atuar (SCHADEN, 1974). Reforçou-se, assim, um caminho interpretativo de que os indígenas, ao apresentarem - ou aparecerem registrados com - comportamentos pouco ou nada convencionais aos padrões ocidentais, são alienados do contexto histórico em que vivem, porque estão apegados a uma estrutura que é inconsciente. ${ }^{3}$

$\mathrm{Na}$ análise de Eduardo Viveiros de Castro (1992), contudo, a guerra e a vingança também aparecem vinculadas como motor da sociedade indígena, porém de forma invertida: a guerra e a vingança existem em função do devir, do vir a ser da sociedade nativa e não como uma retratação de um passado. Ou seja, a guerra está presente como condição para que a sociedade continue a existir no futuro:

A vingança não era assim um simples fruto do temperamento agressivo dos índios, de sua incapacidade quase patológica de esquecer e perdoar as ofensas passadas; ao contrário, ela era justamente a instituição que produzia a memória. Memória, por sua vez, que não era outra coisa que essa relação ao inimigo, por onde a morte individual punha-se a serviço da longa vida do corpo social. [...] O ódio mortal a ligar os inimigos era o sinal de sua mútua indispensabilidade; este simulacro de exocanibalismo consumia os indivíduos para que seus grupos mantivessem o que tinham de essencial: sua relação ao outro, a vingança como conatus vital (VIVEIROS DE CASTRO, 1992, p. 233-234, grifo do autor).

Dessa forma, a compreensão da guerra, nas sociedades indígenas, como condição de sua existência no futuro, traz consigo uma percepção real do contexto histórico vivido juntamente com uma escolha sobre a melhor forma de enfrentá-lo. O questionamento sobre os registros históricos que mostram o reincidente comportamento belicoso dos Kaiapó contra os não indígenas durante os séculos XVIII e XIX, por exemplo, conforme apresentado por Marcel Mano (2011), indica que a guerra se vincula à belicosidade desse grupo - tal como aponta a documentação histórica -, mas também funciona como uma atualização da estrutura mitológica de relação e incorporação do outro - e, em tratando-se dos brancos, havia um lugar reservado à sua acomodação dentro dos mitos (LÉVI-STRAUSS, 1991, p. 66). ${ }^{4}$

Entre os grupos pampianos, enquanto falta um estudo sistematizado de narrativas míticas, abundam os registros históricos de comportamentos pouco convencionais destes grupos acerca da relação, geralmente conflituosa, mantida durante o contato e convívio com os povoados missionais na fronteira. A análise realizada neste estudo se situa entre a falta de um e a abundância de outro.

Temos ainda a concepção de infiel, de longa trajetória na história ocidental e utilizado em profusão na documentação colonial. Cientes da ambiguidade que pressupõe o uso dessa expressão, cabe sublinhar que aqui a utilizamos da forma mais imediata, conforme aparece recorrentemente nos registros coloniais: infiéis são aqueles não cristianizados. Portanto, são vistos, pelos autores dos registros, como aqueles que apresentam comportamentos opostos aos que vivem segundo as normas estabelecidas pelo projeto colonial e, por isso, identificados como inimigos dos indígenas convertidos. Mesmo nessa concepção imediata, cabe sublinhar que a condição de inimigo está dada pelo discurso do missionário (LONDOÑO, 2002; AGNOLIN, 1998; 2007), e não por autodeclaração dos indígenas envolvidos. Nessa medida, como é esperado, o discurso colonial, missionário ou civil, distancia-se da concepção nativa na mesma medida em que se aproxima da percepção ocidental. 
Em outras palavras, os registros que insistem que a guerra se faz na fronteira contra o inimigo a ser combatido e aniquilado devem ser analisados também a partir dos pressupostos que movem os ataques dos grupos não convertidos. Cabe pontuar que a interpretação aqui proposta - que condiciona a utilização da expressão infiéis - não se aplica à extensão apresentada pela documentação colonial, a qual, por exemplo, utiliza a mesma expressão (grupos infiéis) nos combates contra os bandeirantes nas décadas de 1630-1640.

Desta forma, ao longo do período colonial, os conceitos de guerra, fronteira e infiéis oscilam num espaço movediço de significados e intençóes nos registros documentais. Nosso problema debruça-se sobre o que impedia os indígenas, de ambos os lados, cumprirem com as determinações coloniais, como fazer guerra ou atender as cláusulas estipuladas em um tratado de paz, convertendo, assim, o tema combate contra os infiéis em uma sequência de eventos, que se prolongam e se replicam nos registros da documentação da primeira quinzena do século XVIII na América Meridional.

\section{Dos ataques dos Infiéis até a Expedição de Piedrabuena}

A documentação colonial registra que, nos primeiros anos do século XVIII, a América Meridional, especialmente a Banda Oriental do Uruguai, foi palco de uma sequência de ataques dos grupos pampianos (Charruas, Minuanos, Guenoas, Yarós e Mbohanes) às cidades espanholas, povoados missioneiros e estâncias de gado. As cidades de Santa Fé e Corrientes - assim como as missões de Santo Domingo Soriano, Yapeyú, La Cruz e Nossa Senhora dos Reis -, com suas respectivas estâncias de gado, foram alvos constantes de ataques, além de esporádicas ofensivas contra os barcos que navegavam pelos rios Paraná e Uruguai. Tais investidas redundaram em contra-ataques com “expedições punitivas” aos índios fiéis em 1702, 1709 e 1715 (LATINI, 2012, p. 1-2).

O Procurador Geral da Província do Paraguai, Padre Francisco de Burges, em seu Memorial de 1702, registra que, apesar dos crescentes progressos que se verificam em todas as doutrinas encarregadas aos missionários da Companhia de Jesus, "se turba también con el susto, que tienen de ver destruidas sus fatigas por los indios infieles, que viven en su vecindad" e relata sobre a ameaça que é estar tão próximo dos índios infiéis:

En 1701, no haciendo caso estos indios de la Paz que reinaba entre las demás Naciones, a mano armada se apoderaron del lugar de Yapeyú, llamado por otro nombre, de los Santos Reyes; lo saquearon, profanaron la Iglesia, las imágenes y los vasos sagrados, y se llevaron gran cantidad de caballos y vacas; obligó tan deplorable insulto a nuestros neófitos a tomar las armas en su defesa. Les dio el Gobernador de Buenos Ayres por comandante a un Sargento Mayor, con algunos soldados españoles que uniéndose con los Indios, formaron un cuerpo de dos mil hombres; fueron à buscar al enemigo, y le libraron la batalla, en la cual se derramo mucha sangre de una parte y de otra (BURGES, 1702, f. 244).

O registro segue informando que "pidieron los Infieles socorro a los portugueses, y estos se lo dieron”, resultando em mais cinco dias de combate, vencido pela milícia formada pelo governador de Buenos Aires. O objetivo do relato é mostrar "a que peligros está expuesta esta nueva Cristiandad”, principalmente devido à frágil defesa dos povoados, constatando que estas "violencias dañan, lo que no es decible, a la conversión de estos Pueblos”. Frente a isso, havia o receio de que os índios reduzidos pudessem fugir e se distanciar do projeto catequético, comprovando 
a condição movediça da dualidade fiel/infiel: "la inquietud continua en que viven los desparrama por los bosques y montarías, y será imposible detenerlos en los lugares, en que con tanta fatiga los hemos juntado, si no se les procura tranquilidad y sosiego" (BURGES, 1702, f. 244-245).

Outra questão apontada por Francisco de Burges em seu Memorial é a facilidade com que alianças oportunistas são realizadas pelos índios infiéis - nesse caso, com os portugueses. Esse é um aspecto que será pauta de muitos outros registros, pois havia uma recorrência de casos em que indígenas conseguiam estabelecer relações temporárias para fins imediatos, como ataques às reduções, roubos de animais em estâncias ou trocas ilegais, de onde "sacan de ellos alfanjes, espadas y otras armas, en cambio de sus caballos" (BURGES, 1702, f. 244). Por outro lado, observa-se também o rompimento da suposta paz que reinava entre as naçóes e a organização de corpos de combate por parte das autoridades civis do lado espanhol. São aspectos que se repetirão de diferentes formas ao longo da primeira quinzena do século XVIII.

Em janeiro de 1708, o juiz Alonso Juan de Valdés e Inclán apresentou os Autos realizados contra os infiéis para que devolvessem as famílias e o gado roubado (VALDÉS E INCLÁN, 1708). Logo a seguir, temos as reclamações dos missionários pela demora das autoridades civis e eclesiásticas em cumprir com os castigos determinados aos infiéis, que culminaram no Tratado de Paz firmado com os indígenas Charruas (MEDRANO, 1708). Por fim, temos a expedição comandada pelo Mestre de Campo Francisco García Piedrabuena (1715) organizada em função do incumprimento dos grupos pampianos das cláusulas anteriormente firmadas. Nos dois primeiros registros, evidencia-se a ousadia dos grupos não cristianizados contra os povoados de índios missioneiros, em que roubos de gado e cavalos e sequestro de mulheres e crianças tornavam-se cada vez mais frequentes.

Por meio dos autos de Alonso Juan de Valdés e Inclán (1708) e do relatório do Mestre de Campo Francisco García Piedrabueba (1715) ao Governador de Buenos Aires, D. Baltasar García Rosa, é possível ter um panorama da instabilidade desses primeiros anos do século XVIII na região. A introdução do interrogatório promovido por Valdés e Inclán mostra o alcance dos ataques dos grupos pampianos:

[...] dichos indios infieles y demás están apoderados de las vaquerías y demás Pampas y campańas realengas, donde pastan los ganados que recogen para su manutención estorbando el que dichos indios cristianos, llevan el sustento preciso para sus familias y que acometieron el pueblo de Yapeyú y de la Cruz, matando a treinta y ocho personas y cautivando a veinte y seis y en otras ocasiones habiendo muerto a veinte y seis, acometiéndole repentinamente y que mataron como cincuenta personas entre españoles, indios y mulatos cuando estuvieron las tropas de este gobierno sobre la Colonia de Sacramento y fortaleza de San Gabriel (VALDÉS E INCLÁN, 1708, f. 1r).

Além das mortes e raptos, os ataques dos infiéis somaram importantes perdas à Yapeyú, à La Cruz e às suas estâncias, com o furto de “yeguas, vacas mulas y más de trescientos caballos”. Valdés e Inclán roga às autoridades superiores que tomem providências mais efetivas que impeçam os índios infiéis de se aproximarem dos "portugueses u otras naciones extranjeras o aliadas con sus personas y caballos en caso que vengan a invadir estas províncias", a fim de deixar "libres los caminos de comercio, vaquerías y campos que hay entre la una y otra banda del Río Uruguay y Paraná” (1708, f. 1r-1v).

Como se vê, existe uma clara intenção do autor do registro em marcar a presença ofensiva e ameaçadora dos grupos Charruas, Guenoas, Bohanes e Yarós com atitudes pouco cristãs, como 
roubo de animais, morte de espanhóis e sequestro de índios como cativos de guerra. Em função dessas ofensivas e da denúncia do Padre Gabriel Patiño sobre a morte de doze índios Tapes, produziu-se um extenso documento de quase 170 páginas, no qual o juiz Valdés e Inclán juntou testemunhos e interrogatórios recolhidos desde 1705, de forma a registrar os ataques dos grupos infiéis (AUTOS, 1708). Foram interrogados, além de indígenas (tapes) sobreviventes, diversos personagens envolvidos, tais como soldados das tropas espanholas, membros do Cabildo, mestres de campo, moradores das cidades e peóes de estância.

Preocupados apenas em entender a forma como os infiéis atuavam em seus violentos ataques e roubos audaciosos, tanto os interrogadores como as testemunhas, ao ignorar os motivos por trás dessas ações, não podiam imaginar que os índios atuassem por meio de lógicas próprias. Não perceber - ou não querer perceber - que os nativos possuíam uma ordem lógica, dedutiva e reflexiva sobre o mundo que habitavam não era apenas consequência de um preconceito reproduzido pelas gerações de colonizadores, colonos, agentes administrativos e religiosos sobre os indígenas. Era, antes, a ausência do que Roy Wagner chamou de "contexto", ou seja, "um ambiente no interior do qual elementos simbólicos se relacionam entre si, e é formado pelo ato de relacioná-los". Interlocutores só conseguem compreender-se quando “associaçôes convencionais" são efetivas: "a comunicação e a expressão só são possíveis na medida em que as partes envolvidas compartilham e compreendem esses contextos e suas articulações” (WAGNER, 1975, p. 78). Assim, na ausência de comunicação, a outra parte sempre parece desfavorecida de lógica. É justamente quando estamos (e os brancos em relação aos índios na época colonial) “inconscientes dos paradigmas metafísicos subjacentes às nossas próprias compreensões do mundo, enquanto os de outras tradiçốes do conhecimento nos parecem exóticos, improváveis e mesmo 'supersticiosos”" (SCOTT, 1996, p. 72). Disso resulta que o julgamento nos Autos, bem como dos demais agentes coloniais, foi conduzido buscando a reafirmação de ideias pré-concebidas sobre os grupos indígenas.

O interrogatório de Valdés e Inclán apresenta-se como um modelo discursivo civil que reafirma o discurso missionário de então: os ataques dos infiéis são obstáculos que atrasam o processo de realização do modelo de vida cristã entre os índios reduzidos. Entretanto, o que a documentação histórica também evidencia é a sequência de provocações promovidas pelos pampianos fronteiriços. Para além da norma discursiva sobre a ofensa às comunidades cristãs de cidades ou de povoados missioneiros, emolduradas pelo discurso ocidental, o que se vê também é a busca da guerra para a relação. O que está por trás da ação dos pampianos ao raptarem vinte e seis pessoas, matarem outros trinta e oito e roubarem mais de trezentos cavalos não tem como motivo executar a vingança de alguma ofensa do passado, nem tem como intenção desestruturar ou eliminar os grupos atacados. Seus ataques buscam formas de manter a relação como os demais indígenas, utilizando, como estratégia, a captura de bens valorizados no grupo inimigo, na qual - além do roubo de animais, seja para manutenção (gado) ou para transporte (mulas e cavalos) - também gerou a captura de mulheres.

Em fevereiro do mesmo ano de 1708, o Padre Francisco Medrano apresentou uma indignada carta ao Provincial e às autoridades coloniais sobre as ameaças que a presença dos índios pampianos representa às reduçôes de La Cruz e de Yapeyú. Segundo o padre, os infiéis "llevaron 400 yeguas mansas y 20 de la cría y cada día hacían continuos destrozos en dichas estancias”, além de terem matado "cruelmente los 26 inocentes cautivos" raptados de Yapeyú. Frente a isto, organizou-se uma investida militar de retaliação aos índios infiéis. Porém, prevendo um ataque de outras parcialidades às reduçóes, que estariam desprotegidas, foram reunidos 250 soldados para atacar as 
tolderias de infiéis próximas aos povoados. O que se seguiu foi um confronto que "costó la vida de dos de nuestros soldados. De ellos murieron como once personas. Y se apresaron como ciento, los más de la chusma” (MEDRANO, 1708, f. 1v-2r). Em tom de desabafo, no final do relato, o padre Francisco Medrano denuncia a ausência de ações mais efetivas contra os índios por parte das autoridades civis. É taxativo ao afirmar que "el terrible golpe que estos infieles nos acababan de dar, matando a los 26 de Yapeyú”, não pode ficar sem castigo, pois “quedarían insolentísimos”. Contudo, parece não ver a quem recorrer:

Si se aguardara el beneplácito del teniente y Señoría del Cabildo; lo primero no lo darían: porque son grandes defensores de estos infieles, por sus particulares intereses, con hartos daños de la república y escándalo formalísimo de sus hijos. Y lo segundo luego serían sentidos nuestros soldados, y el pájaro se iría de la mano (MEDRANO, 1708, f. 2r).

Depois de três tentativas infrutíferas de estancar os conflitos, foi proposto, no ano seguinte, um acordo de paz entre os Charruas e os indígenas das missóes, obrigando os primeiros a permanecerem em suas terras e a aceitarem o estabelecimento de um Corregedor espanhol e a presença de um sacerdote em seus domínios. Com o objetivo de iniciar uma trégua entre as partes e assegurar a paz, foram firmados seis pontos que revelam o comportamento que as autoridades coloniais esperavam dos Charruas, tais como evitar alianças com os demais grupos infiéis (Yaros, Guenoas, Mbohanes), devolver as mulheres raptadas e não atacar as embarcações que cruzassem os rios (RELACIÓN, 1709).

Firmar a paz com grupos indígenas a fim de encerrar um conflito e, principalmente, estabelecer uma aliança com quem antes se tinha a inimizade não era uma aposta à resignação indígena, mas, sim, o resultado da falta de investimento por parte da Cora, que evitava dispender gastos com a colônia (CRIVELLI MONTERO, 2004, p. 347). Assim, o principal desejo de um tratado de paz bem executado era conseguir amansar grupos hostis e, além disso, poder contar com seu apoio na defesa das cidades e estâncias.

Contudo, ainda que assinassem o mesmo documento, índios e espanhóis não o faziam a partir dos mesmos significados. Os tratados de paz tinham como objetivo, para os representantes coloniais, enquadrar "los grupos nativos implicados en los acuerdos dentro de ciertos marcos legales". Sabiam, contudo, que a celebração de um tratado não "garantizaba una obediencia leal y absoluta", pois as "acciones de los indígenas implicados en este tipo de fórmulas no dan cuenta de una aceptación real de la autoridad real” (LUCAIOLI, 2014, p. 393). Isto se deve ao fato de que, mesmo quando acreditavam estar falando sobre o mesmo assunto, "las diferentes matrices culturales de indígenas y españoles cargaban los conceptos de significaciones divergentes” (ROULET, 2004 , p. 340). Para os indígenas, o acordo oferecido pelos espanhóis na forma de tratado de paz não se comunicava nos mesmos termos que a sua concepção de relacionamento, que era baseada na sociabilidade, e não na diplomacia:

Assim, os objetivos destes acordos de aproximação entre os colonos e os nativos divergiam de tal forma que, aosíndios, era interessante criar essas alianças com os espanhóis buscando novas formas de enriquecer materialmente seus conflitos. E não só as alianças em si, mas também as armas providenciadas para as reduçôes jesuíticas somaram uma importante vantagem à dinâmica da guerra indígena (FELIPPE, 2015, p. 287). 
As instabilidades decorrentes da divergência de interesses e significados consignados aos acordos selados entre hispano-crioulos e indígenas ficam bastante aparentes quando, mesmo depois de firmar tratado de paz com os Charruas em 1709, uma campanha de "castigo de los charrúas y otros infieles, que con sus insultos, muertes y robos inquietaban la tierra e impedían los caminos de ambos ríos Paraná y Uruguay", é realizada entre novembro de 1715 e janeiro do ano seguinte. Esta "expedición y pacificación de la tierra y castigo de los infieles” foi organizada pelo Mestre de Campo Francisco García de Piedrabuena, "cabo comandante de los españoles, e indios tapes [Guaranis]", que registrou os detalhes da investida em um informe destinado ao governador de Buenos Aires, Baltazar García Ros (PIEDRABUENA, 1716, f. 1r). O relatório de Piedrabuena dá-nos informaçôes complementares acerca de comportamentos pouco ortodoxos dos indígenas, inclusive sobre as negociaçôes e aproximações com o inimigo infiel.

Partindo no dia oito de novembro de Yapeyú, depois de revisar toda "la gente y registro general de las armas y cabalgaduras" - pontuando que "siendo la gente toda de la mejor y más escogida; y lo demás del avío en abundancia todo, sin que los Reverendos Padres me negasen cosa alguna de las que yo insinué para el mejor logro de la dicha expedición” (PIEDRABUENA, 1716, f. 1r-1v) -, a marcha dos soldados comandados pelo Mestre de Campo Francisco García de Piedrabuena seguiu em direção sul, até o rio Mocoreta, onde se encontrou com outra tropa que se somou à expedição. Um dos integrantes deste destacamento indicou a Piedrabuena onde estariam os toldos dos Charrua que deveriam ser atacados. Rumando nesta direção, chegaram ao acampamento comandado pelo Sargento Mayor Francisco Carvallo, onde "se nos agregaron quince infieles Guenoas amigos, con quienes juntos, marchamos en busca del enemigo" (PIEDRABUENA, 1716, f. 1v, grifo nosso). Logo depois, ao passar pelo rio Gualeguaychu, a expedição de Piedrabuena recebeu informações sobre acampamentos de índios infiéis, liderados pelo cacique Caraví, com vinte e cinco toldos de gente inimiga. Para averiguar a situação, Piedrabuena envia o Capitão Marcelo Martínez "acompañado de otro español, de un pardo, y de seis guenoas, con orden mía que los prendiesen; y en caso de resistirse se valiesen de las armas. Lo cual ejecutaron fielmente" (PIEDRABUENA, 1716, f. 2r).

Os Guenoas, na narrativa do Mestre de Campos, são o "quase-nós” que François Hartog indica como "essa outra alteridade" (ou a "alteridade em segundo grau”) que não é nem "nós”, mas também não exatamente "eles” (1980, p. 365, grifo do autor). Os infiéis, que não são diplomaticamente aliados, mas são temporariamente amigos, porque são inimigos dos inimigos dos espanhóis. Na prática, esta aliança temporária atingiu seu efeito desejado, quando as tropas hispano-crioulas alcançaram o acampamento inimigo e nos renderam com a ajuda dos Guenoas infiéis: "Entonces un indio llamado Ignacio Lezcano se puso en defensa; pero habiéndole hablado el Cabo [Don Antonio de Vera], se entregó. Otro de nación Boan [sic], no obstante que se puso en fuga, fue apresado con dos mujeres, y una criatura. Dicho indio Bojan volvió a hacer fuga; mas [sic] los indios guenoas le quitaron luego la vida” (PIEDRABUENA, 1716, f. 2r).

Como se vê, a tropa de Piedrabuena, formada para castigar os infiéis, recebe ajuda de Guenoas infiéis, tidos antes como inimigos. Enquanto os Guenoas se aliam aos espanhóis, os Bohanes tentam escapar da ameaça representada pela presença da tropa de Piedrabuena. Se buscarmos a lógica do autor do informe, veremos a tentativa de passar a informação de que alguns esforços de cristianização estão surtindo efeito, ainda que esporadicamente. Os acordos, fugas ou alianças ocasionais são vistos, desde a lógica ocidental, como a excę̧ão que confirma a regra. Tais comportamentos são mais compreensíveis dentro da lógica de guerra nativa, na qual guerra e inimizade não são circunstâncias postas de forma estanque e imutável. 
Se, por um lado, a tropa dos indígenas cristãos comandada por Piedrabuena recebeu apoio e aliança de alguns infiéis, por outro, os acampamentos dos infiéis tampouco eram homogêneos. O relato de Piedrabuena sobre a morte do cacique Caravi - liderança reconhecida dos infiéis evidencia a diversidade étnica compartilhada pelos indígenas. Depois de ser avisado que um índio infiel espião estava infiltrado em uma das tropas espanholas, Piedrabuena deu a ordem para que o capturassem enviando:

[...] algunos españoles de los que iban conmigo y algunos de las tropas, que allí estaban, con algunos indios tapes y guenoas en busca de dicho indio [espía], dieron de repente con el indio infiel Caravi con otros cuatro de su nación y un guaranicito de ocho años del pueblo del Yapeyú. Y habiéndose puesto en resistencia, mataron al dicho Caravi y a tres de sus compañeros, cogiendo al guaranicito (PIEDRABUENA, 1716, f. 2v, grifo nosso).

A presença de uma criança Guarani, nascida na redução de Yapeyú, entre os Charrua infiéis é um exemplo empírico do resultado de um mecanismo sociológico bastante difundido entre grupos indígenas da regiáo da bacia do Rio da Prata: o apresamento de cativos de guerra com a finalidade de estabelecer resgates ou trocas com outros grupos ou com os hispano-crioulos (NÉSPOLO, 2008), ou a sua incorporação no grupo como membro cognático carregado de uma subjetividade outra (FELIPPE, 2016, p. 127). Devido às escassas informaçôes que o autor do documento fornece em relação à situação em que se encontrava a criança, ou o contexto que a levou para dentro do acampamento dos Charrua, resta apenas deduzir que o "guaranicito" foi capturado em algum embate entre os índios infiéis e os moradores de Yapeyú e que, por estar junto do cacique, seu destino era permanecer junto a seus captores. Isso deixava tudo mais complexo para os espanhóis que acreditavam na eficácia dos tratados de paz acordados com indígenas: o que esperar de quem tem em seus inimigos a possibilidade de um vir a ser? (VIVEIROS DE CASTRO, 1992).

$\mathrm{Na}$ verdade, a expedição de Piedrabuena mostra-nos que, durante a disputa registrada na documentação contra os infiéis, mesclam-se diferentes interesses, e os grupos, de um lado e de outro, não mantinham relações estanques nem tampouco previsíveis. Duas situaçóes relatadas em sequência por Piedrabuena exemplificam a volatilidade das relações. Na primeira, já em dezembro, um grupo de Guenoas que estava aliado à tropa hispano-crioula avistou três Yaros e, depois de atacarem-nos, mataram um dos infiéis e aprisionaram um cacique. Este, aprisionado, declarou que um "español barbón amulatado había dado noticia a los infieles” sobre o avanço dos soldados de Piedrabuena e "como dichos infieles podían hurtándonos la vuelta hacernos algún daño" (PIEDRABUENA, 1716, f. 3r). Mesmo em guerra com os hispano-crioulos, os Yaros não deixaram de manter contato com os espanhóis, inclusive, para receber informações sobre as tropas. ${ }^{6}$

Dias depois, desembarcaram aliados da redução de Santo Domingo Soriano para juntarem-se à tropa de Piedrabuena. Entre eles “aparecieron algunos indios, que antes se habían visto entre los infieles; y preguntados, respondieron que se habían incorporado con ellos, por haber ido acompañando a un fulano Joseph Gómez de Santa Fe” (PIEDRABUENA, 1715, f. 4r). A facilidade e rapidez com que os índios mudavam de lado na guerra não parecia mais surpreender o autor do relato. De qualquer forma, foi motivo suficiente para que, no final do informe, ressaltasse o bom comportamento dos índios que o acompanharam na expedição, pontuando sua obediência ao portarem-se "escogidamente de bien, mostrando su valor, sujeción y rendimiento en cuanto se ha ofrecido y yo les he mandado, sin desmán alguno de ellos, ni conmigo ni con los españoles mis 
compañeros, ni menos entre sí”. Reforçar que os nativos foram "obedientes a sus oficiales mayores y menores, portándose en todo como leales vasallos de su Majestad” (PIEDRABUENA, 1715, f. 4v) é antes uma forma de o autor destacar as conquistas da expedição do que um elogio direto aos nativos. Ao constatar que a campanha contra os infiéis não havia alcançado os resultados pretendidos e um grande desgaste já se abatia contra sua tropa, no dia dois de janeiro foi formada uma junta de guerra para "poder deliberar sobre desistir, o continuar la campaña”. A consulta aos cabos de sua companhia fê-lo perceber que a expedição deveria ser abortada e "sería consejo más acertado el retirarse a sus pueblos para en otro tiempo más oportuno proseguir la empresa ya comenzada" (PIEDRABUENA, 1715, f. 4r-4v). Como resultado da expedição e de toda a mobilização dos grupos cristãos contra infiéis, contabilizaram-se a morte do cacique Caravi e de quatro prisioneiros, sendo um deles o "guaranicito" de oito anos do povoado de Yapeyú, que morreu no caminho, e Ignácio de Lezcano, índio batizado, que foi reencaminhado à vida cristã, pois esteve muitos anos entre os índios infiéis. Quanto aos outros dois infiéis capturados, foram entregues ao Padre Superior, que se responsabilizou por lhes dar cuidado, catecismo, batismo e casamento cristão (PIEDRABUENA, 1716, f. 5r).

Ao final dessa contenda, não se vê o reforço de uma das posiçôes como vencedora, tampouco o esforço de garantir a paz na convivência de índios cristãos e não cristãos. Não parece ser um resultado muito promissor para todo o esforço envolvido na formação das tropas do "exército cristão".

\section{Considerações finais}

O discurso colonial sobre indígenas apresenta diversas camadas de interpretação, as quais cabem ao historiador identificar e explorar. As descrições religiosas ou civis das atitudes dos grupos nativos não convertidos em contato com os indígenas sob convívio reducional insistem na qualificação dos primeiros como pouco aptos a compreender as regras do mundo colonial. Os roubos de gado, de cavalos ou os raptos de mulheres e crianças aparecem num "discurso de superfície” (WAGNER, 1975), preponderantemente como atitudes inconscientes e inconsequentes. A desqualificação do humano sobre o registrado, muito em voga no século XVII, passou a ter uma consequência avassaladora no século XVIII. Os infiéis roubam gado, cavalos e mulheres porque não entendem as regras da vida cristã, ou seja, agem, porque estão sob o signo da barbárie. Compreender os infiéis a partir desse pressuposto é assumir como verdadeira a primeira camada do discurso colonial, que nos coloca diante de qualificações externas e discursivas sobre o outro.

Mas, a produção do discurso colonial, em particular sobre a guerra e os infiéis, também pode ser vista com as propriedades da relação, conforme apontou Strathern (2014, p. 281). A guerra e os infiéis, no início do século XVIII, deslocam-se por múltiplas escalas sem perderem a propriedade de serem complexas, porque reproduzem as interferências do objeto a ser descrito (guerra/infiéis) e do autor do registro (missionário/civil).

Desde o século XVI até o XVIII, guerra, fronteira e infiéis foram conceitos que oscilaram num espaço de diversos significados e intenções nos registros coloniais. A utilização do termo infiel nos escritos missionários atendia mais a uma prescrição discursiva entre o aceitar ou não a predicação católica, enquanto os grupos indígenas classificados com o referido termo apresentavam um comportamento vinculado mais às categorias próprias do que à aceitação e à inserção na conjuntura colonial. 
Mas, esse espaço movediço foi constantemente assaltado. Primeiro pela sucessão de ataques de grupos Charruas, Minuanos, Guenoas e Bohanes, e depois recortado pela sequência de tratados de limites entre Portugal e Espanha. Nesse ínterim, gestam-se outras relações para além das disputas políticas e diplomáticas entre as metrópoles ibéricas ou os limites da ocupação entre indígenas cristianizados e os não convertidos.

A documentação histórica apresenta vários registros dos ataques dos grupos pampianos às reduçôes jesuíticas lindeiras, como Yapeyu e La Cruz. Nos ataques, destacam-se ações como o roubo de gado, cavalos e pessoas. Como resposta, inúmeras tentativas de investigações acerca dos crimes cometidos, interrogatórios e acordos de paz estabelecidos entre os grupos pampianos e membros da sociedade colonial (religiosos ou civis) foram realizados em busca de tréguas e da boa convivência na região, cujos resultados foram sempre duvidosos e parcamente cumpridos pelos indígenas de ambos os lados - infiéis ou reduzidos, os pampianos nunca deixaram de responder "a un proceso de selección propio, organizado en torno a las particularidades productivas diseñadas por los propios actores” (NÉSPOLO, 2008, p. 3). Ora os pampianos voltavam a atacar as reduçôes e suas vacarias, ora os Guaranis reclamavam das ofensas recebidas, pleiteando apoios coloniais contra os grupos denominados como infiéis. Ainda que tais atitudes oscilantes possam ser entendidas superficialmente como evidências da inconstância da alma selvagem diante das novidades de um novo momento colonial (GARCIA, 2011), elas também podem ser a expressão da constância de determinados comportamentos estruturais das sociedades indígenas em questão. Se os infiéis roubam gado e cavalos das estâncias missioneiras, sequestram mulheres, fazem cativos ou deixam de cumprir as cláusulas de um Tratado de Paz anteriormente assinado, isso deve nos levar a repensar sobre o motor dessas atitudes, antes de reafirmar o discurso colonial e caracterizá-las como um comportamento bárbaro e inapto para os padróes da sociedade cristã. Deve-se questionar um pouco mais - ou de diferentes formas - os registros coloniais que trazem afirmaçóes com uma compreensão a priori acerca dos motivos de fazer a "guerra aos infiéis".

Se a Nova História Indígena quer mostrar o indígena na História, que busque se esforçar para mostrar o que há de nativo nos registros coloniais e não somente o que há de aprendizado ocidental com uma aparência nativa, tais como os personagens com nome e sobrenome destacados pelo autor do documento. A análise que dá destaque ao autor/indivíduo indígena não deve ignorar a potencialidade da ação coletiva e estrutural de um grupo nativo sob o risco de incorrer na "ilusão biográfica”, ou seja, "encontrar os motores do passado e do presente no individualismo racional e prestar pouca atenção às formas sociais e culturais que silenciosamente moldam e restringem a ação humana" (COMAROFF, John; COMAROFF, Jean, 1992, p. 26). ${ }^{7}$ Dessa forma, só se evidenciará o quanto os indígenas demoraram em aprender a serem ocidentais ou marginais e, portanto, menos indígenas. Enfatizar o discurso do desenvolvimento de estratégias e do uso dos recursos coloniais à disposição dos indígenas, embora seja um ato passível de ser travestido como "dar voz aos indígenas", mostra-nos mais, na verdade, sobre o aprendizado de uma subalternidade esperada e desejada da sociedade colonial, não da indígena. Ressaltar as lógicas próprias da sociedade nativa, sob diferentes circunstâncias, nem sempre é imediato na análise da documentação colonial, mas sublinha a capacidade dessas sociedades de lerem e atuarem na conjuntura histórica em que estão inseridas, a partir de sua estrutura interna. Por isso mesmo, suas atitudes, a partir dessa estrutura, são lógicas e não atos inconscientes. 


\section{Referências}

ACOSTA Y LARA, Eduardo. La guerra de los Charrúas en la Banda Oriental. Período Hispánico. Montevidéo: Impresores A. Monteverde y Cia S.A., 1961.

ACOSTA Y LARA, Eduardo. La Guerrra de los Charrúas en la Banda Oriental. Período Patrio I e II. Montevidéo: Linardi y Risso, 1989.

AGNOLIN, Adone. O apetite da Antropologia, o sabor antropofágico do saber antropológico: alteridade no caso Tupinambá. São Paulo: Associação Editorial Humanitas, 2005.

AGNOLIN, Adone. Jesuítas e Selvagens: a negociação da fé no encontro catequético-ritual americano-tupi (séculos XVI-XVII). São Paulo: Humanitas, 2007.

ALBERT, Bruce. A fumaça do metal: história e representações do contato entre os Yanomami. Anuário Antropológico, n. 89, p. 151-189, 1992.

AUTOS de las hostilidades de indios Guenoas contra os Guaraníes. Buenos Aires, 1705-1708. Manuscritos da Coleção De Angelis; Biblioteca Nacional do Rio de Janeiro: rolo 20, doc. 19-543 (I-29-3-70).

BAPTISTA, Jean. Matar um jaguar: a natureza na cultura guarani através do discurso missionário. História Unisinos, São Leopoldo, v. 9, n. 1, p. 61-64, 2005.

BRACCO, Diego. Los guenoa minuanos misioneros. Memoria Americana. Cuadernos de Etnohistoria, v. 24 , n. 1, p. 33-54, 2016.

BURGES, Francisco. Memorial del Padre Procuradore Geral da Província do Paraguai sobre as Missões dos Chiquitos e dos rios Paraná e Uruguai. In: CORTESÃO, Jaime (org.). Manuscritos da Coleção De Angelis, v. VI: antecedentes do Tratado de Madrid. Rio de Janeiro: Biblioteca Nacional do Rio de Janeiro; Divisão de Obras Raras e Manuscritos, 1966. p. 231-245.

COMAROFF, John; COMAROFF, Jean. Ethnography and the Historical Imagination. Boulder: Westview Press, 1992.

CRIVELLI MONTERO, Eduardo. Pactando con el enemigo: la doble frontera de Buenos Aires con las tribus hostiles en el período colonial. In: CIPOLLETTI, María Susna (org.). Los mundos de abajo u los mundos de arriba: individuo y sociedad en las tierras bajas, en los Andes y más allá. Quito: Abya-Yala, 2004. p. 313-356.

FELIPPE, Guilherme Galhegos. A cosmologia construída de fora: a relação com o outro como forma de produção social entre os grupos chaquenhos no século XVIII. Jundiaí: Paco Editorial, 2014.

FELIPPE, Guilherme Galhegos. Estar, e não ser, aliado: a sociabilidade dos índios do Chaco durante o avanço colonial no século XVIII. Anos 90, Porto Alegre, v. 22, n. 41, p. 267-298,2015. DOI: doi.org/10.22456/1983-201X.43129.

FELIPPE, Guilherme Galhegos. A lógica do mito e o lugar do Outro entre os índios do Chaco. História Unisinos, São Leopoldo, v. 20, n. 2, p. 120-130, 2016. DOI: doi.org/10.4013/htu.2016.202.01.

FERNANDES, Florestan. A função social da guerra na sociedade tupinambá. São Paulo: Pioneira; Edusp, 1970.

GARCIA, Elisa Frühauf. Identidades e Políticas Coloniais: guaranis, índios infiéis, portugueses e espanhóis no Rio da Prata, c. 1750-1800. Anos 90, v. 18, n. 34, p. 55-76, 2011.

GINZBURG, Carlo. O inquisidor como antropólogo. In: GINZBURG, Carlo. O fio e os rastros: verdadeiro, falso, fictício. São Paulo: Companhia das Letras, 2007. p. 280-293.

GOLIN, Tau. A fronteira: governos e movimentos espontâneos na fixação dos limites do Brasil com o Uruguai e a Argentina. v. 1. Porto Alegre: L\&PM, 2002.

GOW, Peter. An Amazonian Myth and its History. Oxford: Oxford University Press, 2001.

GUAZZELLI, Cesar Barcellos; FLORES, Mariana Flores da Cunha; AVILA, Arthur Lima de. Fronteiras americanas: teorias e práticas de pesquisa. Porto Alegre: Suliani Letra e Vida, 2009.

HERZOG, Tamar. Frontiers of possession: Spain and Portugal in Europe and the Americas. Cambridge: Harvard University Press, 2015.

HUGH-JONES, Stephen. The Gun and the Bow. Myths of White Men and Indians. L'Homme, v. 28, n. 106-107, p. $138-155,1988$ 
LATINI, Sergio Hernán. Relatos del conflicto interétnico: Francisco García de Piedrabuena contra los “charrúas y otros infieles". Corpus, v. 2, n. 2, 2012. DOI: doi.org/10.4000/corpusarchivos. 853 .

LÉVI-STRAUSS, Claude. Guerra e comércio entre os índios da América do Sul. In: SCHADEN, Egon. Leituras de Etnologia Brasileira. São Paulo: Companhia Editora Nacional, 1976. p. 345-363.

LÉVI-STRAUSS, Claude. Antropolgía Estructural. Barcelona: Paidós, 1987.

LÉVI-STRAUSS, Claude. O homem nú (Mitológicas 4). São Paulo: Cosac Naify, 2014.

LÉVI-STRAUSS, Claude. Histórias de Lince. São Paulo: Companhia das Letras, 1993.

LONDOÑO, Fernando Torres. Escrevendo cartas. Jesuítas, escrita e missão no século XVI. Revista Brasileira de História, v. 22, n. 43, p. 11-32, 2002.

LÓPEZ MAZZ, José María; BRACCO, Diego. Apuntes y notas para la Historia y la Arqueología del territorio guenoa-minuano (indígenas de Uruguay, Argentina y Brasil). Montevidéo: Linardi y Risso, 2010.

LUCAIOLI, Carina Paula. Negociación y diplomacia en las fronteras del Chaco: Nuestra Señora de la Concepción de Abipones. Revista História e Cultura, v. 3, n. 2, p. 380-405, 2014.

LUZ, Guilherme Amaral. Carne humana: a retórica do canibalismo na América portuguesa quinhentista. Campinas: UNICAMP, 2003

MANO, Marcel. Contato, Guerra e Paz. Problemas de tempo, mito e história. Política e Trabalho: Revista de Ciências Sociais, n. 34, p. 193-212, 2011.

MEDRANO, Francisco. Cartas del padre Francisco Medrano del estado o motivos de la guerra que se hace a los indios Guanoas, Yaros y Mbohas. San Borja, 24 fev. 1708. Manuscritos da Coleção De Angelis; Biblioteca Nacional do Rio de Janeiro: rolo 20, doc. 20-544 (I-29-3-71).

MELO, Karina Moreira Ribeiro da Silva e. Histórias indígenas nos contextos de formação dos Estados argentino, brasileiro e uruguaio (1801-1818). Tese (Doutorado em História Social) - Programa de Pós-Graduação em História, UNICAMP, Campinas, 2017.

NÉSPOLO, Eugenia Alicia. Cautivos, ponchos y maíz. Trueque y compraventa, "doble coincidencia de necesidades" entre vecinos e indios en la frontera bonaerense. Los pagos de Luján en el siglo XVIIII. Revista Tefros, v. 6, n. 2, p. 1-20, 2008.

PIEDRABUENA, Francisco García. Informe del Maestre de Campo Francisco García Piedrabuena al Gobernador de Buenos Aires, Don Baltaasar García Ros, sobre lo sucedido al castigo de los infieles. Buenos Aires, 12 fev. 1716. Manuscritos da Coleção De Angelis; Biblioteca Nacional do Rio de Janeiro: rolo 21, doc. 21-566 (I-29-3-94).

RELACIÓN de la paz hecha con los Charrúas y del modo de asegurarla. 1709. Manuscritos da Coleção De Angelis; Biblioteca Nacional do Rio de Janeiro: rolo 21, doc. 1-546 (I-29-3-73).

RIBEIRO, Fernando Victor Aguiar. A tese da fronteira de Frederick Jackson Turner na historiografia brasileira no século XX. Labirinto, v. 22, ano XV, p. 214-240, 2015.

ROULET, Florencia. Con la pluma y la palabra. El lado oscuro de las negociaciones de paz entre españoles e indígenas. Revista de Indias, v. 64, n. 231, p. 313-348, 2004.

SANTOS, Maria Cristina dos. Caminhos historiográficos na construção da História Indígena. História Unisinos, v. 21, n. 3, p. 337-350, 2017. DOI: doi.org/10.4013/htu.2017.213.04.

SCHADEN, Egon. Aspectos fundamentais da cultura guarani. São Paulo: Edusp, 1974.

SCOTT, Colin. Science for the West, Myth for the Rest? The Case of James Bay Cree Knowledge Construction. In: NADER, Laura (org.). Naked Science: Anthropological Inquiry into Boundaries, Power, and Knowledge. Londres: Routledge, 1996. p. 69-86.

STRATHERN, Marilyn. No limite de uma certa linguagem. Mana, v. 5, n. 2, p. 157-175, 1999.

STRATHERN, Marilyn. O efeito etnográfico e outros ensaios. São Paulo: Cosac Naify, 2014.

TOLA, Florencia. Eu não estou só(mente) em meu corpo: a pessoa e o corpo entre os Toba (Qom) do Chaco argentino. Mana, v. 13, n. 2, p. 499-519, 2007. 
TOLA, Florencia. Acortando distancias. El Gran Chaco, la antropología y la antropología del Gran Chaco. In: TOLA, Florencia; MEDRANO, Celeste; CARDIN, Lorena (org.). Gran Chaco. Ontologías, poder, afectividad. Buenos Aires: Asociación Civil Rumbo Sur, 2013. p. 11-37.

TOLA, Medrano; MEDRANO, Celeste; CARDIN, Lorena. Gran Chaco. Ontologías, poder, afectividad. Buenos Aires: Asociación Civil Rumbo Sur, 2013.

TURNER, Frederick Jackson. The significance of the frontier in American history. In: TURNER, Frederick Jackson. Rereding Frederick Turner. Londres: Yale University Press, 1999. p. 31-60.

VALDÉS E INCLÁN, Alonso Juan de. Intimación hecha a los indios infieles de devolver las familias y el ganado robado a los de las misiones del Uruguay. Buenos Aires, 30/01/1708. Manuscritos da Coleção De Angelis; Biblioteca Nacional do Rio de Janeiro: rolo 20, doc 18-542 (I-29-3-69).

VALLE, Ivonne del. Escribiendo desde los márgenes: colonialismo y jesuitas en el siglo XVIII. México: Siglo XXI, 2009.

VILAÇA, Aparecida. Quem somos nós: os Wari' encontram os brancos. Rio de Janeiro: Editora UFRJ, 2006.

VIVEIROS DE CASTRO, Eduardo. O mármore e a murta: sobre a inconstância da alma selvagem. In: VIVEIROS DE CASTRO, Eduardo. A Inconstância da Alma Selvagem. São Paulo: Cosac Naify, 2002. p. 181-264.

WAGNER, Roy. A invenção da cultura. São Paulo: Cosac Naify, 2010.

\section{Notas}

${ }^{1}$ No projeto colonial e evangelizador na América Meridional, os inimigos tradicionais sempre foram os grupos dos Charruas, Minuanos, Guenoas e Bohanes. Na historiografia, alguns autores já se ocuparam da temática em suas pesquisas. Acosta y Lara discorre sobre a guerra dos Charruas da Banda Oriental desde o período hispânico até as guerras de independência onde se encontra a clássica referência sobre o "desaparecimento da etnia Charrua", apresentando os registros documentais do envio para a França dos cinco últimos sobreviventes dos combates de Salsipuedes e Matojos (ACOSTA Y LARA, 1961 e [1969-70], 1989). Depois, temos López Mazz e Diego Bracco (2010) que buscam questionar o conceito de macro etnia charrua, grosso modo, eleita pela população uruguaia como referência de um passado indígena homogêneo. Os autores chamam atenção justamente para a pluralidade étnica registrada na documentação colonial (LÓPEZ MAZZ; BRACCO, 2010). Em um texto mais recente, Diego Bracco (2016) analisa justamente como a documentação de origem jesuítica criou generalizações étnicas como 'guarani missioneiro' por oposição aos grupos não convertidos, ocultando a diversidade étnica e cultural dos indígenas coloniais.

2 Segundo a autora, a relação é holográfica "por ser uma instância do campo que ocupa”, ou seja, "cada uma de suas partes contém informações sobre o todo e há informações sobre o todo envoltas em cada uma de suas partes"; e ela também é complexa, pois "precisa que outros elementos a completem, visto que sempre há de se perguntar entre quais elementos as relações se estabelecem", já que "a relação sempre convoca outras entidades diferentes dela própria" (STRATHERN, 2014, p. 277-279).

${ }^{3}$ A vinculação entre estrutura e inconsciente, assinalada por Lévi-Strauss (1962), marca a divisão para um determinado tipo de análise histórica como "um elemento complicador das relações entre História e Antropologia" (MACKAY, 19811982, p. 193 apud ALMEIDA, 2003, p. 30-31), de maneira que, ao valorizar o aspecto estrutural das sociedades indígenas, estaríamos retirando-Ihes a consciência de seu ser e estar no mundo colonial. Nessa perspectiva, as atitudes indígenas pouco convencionais não deveriam ser consideradas na análise histórica, pois induziriam ao equívoco de ver os indígenas como ausentes ou inconscientes da conjuntura em que viviam. Entretanto, estudos como os de Florencia Tola $(2007,2013)$ e Guilherme Felippe (2014) evidenciam que "a compreensão da estrutura pode ser explicativa e fonte de novos questionamentos sobre os indígenas e seus comportamentos registrados na documentação histórica" (SANTOS, 2017). Em suma, se a análise sincrônica deve levar a uma análise diacrônica - como defende Peter Gow (2001, p. 13) em sua defesa a um retorno mais atento às Mitológicas de Lévi-Strauss -, acreditamos que o inverso também é verdadeiro.

${ }^{4}$ Este é um fenômeno bastante descrito pela literatura especializada em estudos sobre a mitologia de povos indígenas, tendo como clássico o artigo de Stephen Hugh-Jones (1988), cuja premissa é a inclusão dos brancos nos mitos dos Barasana, povo Tucano da Amazônia colombiana. Segundo Hugh-Jones, o surgimento do homem branco na mitologia indígena não é a derivação de um estranhamento do contato: o autor deixa claro que o "contato entre culturas é tão antigo quanto a sociedade" (1988, p. 138), não havendo diferença, neste sentido, do contato com os brancos. Estes, bem como suas armas, já estavam previstos dentro do esquema no qual o mito está baseado, em que grupos hostis ou estrangeiros são elementos pré-existentes na narrativa, como, por exemplo, na forma de irmãos ancestrais que se separaram, como é o caso dos brancos. Assim, os seringueiros que contataram os Barasana e os receberam com tiros de arma de fogo tiveram 
imediatamente garantido o seu espaço nos mitos, que "fornecem um repositório de ideias alternativas, interpretações e cursos de ação com potencial aplicação no presente" (1988, p. 151). Esta é uma constatação bastante difundida entre grupos ameríndios, como perceberam, por exemplo, Eduardo Viveiros de Castro (1992) entre os Tupinambá e os Araweté; Bruce Albert (1992) entre os Yanomami; Aparecida Vilaça (2006) entre os Wari'; e Peter Gow entre os Piro, cuja história de conflitos e violência com seringueiros não impediu que os brancos ocupassem seu lugar na mitologia, já que, segundo o autor, os "mitos são, eles próprios, produtos históricos que carregam dentro de si os vestígios daquilo que eles procuram apagar, seus próprios estados anteriores" (2001, p. 303).

${ }^{5}$ O rapto de mulheres e crianças realizado por grupos indígenas que habitavam a região da Bacia do Rio da Prata, o Chaco e o Pampa é uma ação bastante registrada na documentação colonial. Por representarem elementos que compunham a esfera externa, o cativo de guerra possuía uma perspectiva importante para a composição da sociabilidade interna do grupo raptor, carregando, assim, "subjetividade outra, uma possibilidade de se ter acesso ao que é de fora” (FELIPPE, 2016, p. 127, grifo do autor). No caso das mulheres, a sua internalização no grupo são o que Marilyn Strathern chamou de itens de riqueza transformadores, pois a direção em que elas se deslocam cria diferentes tipos de pessoa, já que envolvem "os agentes masculinos numa rede de débitos e créditos, de modo que os homens passam a ser definidos pelo modo como encaram um ao outro como participantes de transações em relação de parentesco". O resultado disto, é que o "fluxo de bens entre homens força tanto os homens como as mulheres a assumirem perspectivas uns sobre os outros" (STRATHERN, 2014, p. 397).

${ }^{6}$ E foram justamente estas notícias que permitiram um ataque surpresa por parte dos índios infiéis, que acometeram três índios das tropas de Piedrabuena, matando dois - sendo um deles, o cacique da redução de San Nicolás (PIEDRABUENA, 1716 , f. 2v)

${ }^{7}$ Os autores completam a crítica com uma interessante metáfora: "um teatro em que, à medida que o holofote narrativo se estreita cada vez mais sobre os atores e seus roteiros, o texto - um triste substituto da vida - torna-se tudo. E o contexto se dissolve em muitas sombras" (COMAROFF, John; COMAROFF, Jean, 1992, p. 26).

Data de recebimento: 21/04/2019

Data de aprovação: 31/10/2019 